\title{
Testosterone Combined with Voluntary Exercise Attenuates Diabetes-induced Pancreatic Apoptosis in Castrated Diabetic Rats Induced by HFD/STZ
}

Leila Chodari ${ }^{1,2}$

https://orcid.org/0000-0002-9263-8583

\section{Bagher Pourheydar 2,3}

https://orcid.org/0000-0001-9823-6887

Hassan Dariushnejad ${ }^{4,6}$

https://orcid.org/0000-0003-2477-9461
Shahriyar Jamshidi ${ }^{5}$

https://orcid.org/0000-0002-0929-3888

\author{
Naser Khalaji ${ }^{1}$ \\ https://orcid.org/0000-0002-6538-1495 \\ Vajihe Ghorbanzadeh ${ }^{*}$ \\ https://orcid.org/0000-0002-4195-3516
}

${ }^{1}$ Urmia University of Medical Sciences, Faculty of Medicine, Department of Physiology, Urmia, Iran; ${ }^{2}$ Urmia University of Medical Sciences, Neurophysiology Research Center, Urmia, Iran; ${ }^{3}$ Urmia University of Medical Sciences, Faculty of Medicine, Department of anatomical sciences, Urmia, Iran; ${ }^{4}$ Lorestan University of Medical Sciences, Department of biotechnology, Khorramabad, Iran; ${ }^{5}$ Urmia University of Medical Sciences, Faculty of Medicine, Urmia, Iran; ${ }^{6}$ Lorestan University of Medical Sciences, Razi Herbal Medicines Research Center, Khorramabad, Iran.

Editor-in-Chief: Paulo Vitor Farago

Associate Editor: Paulo Vitor Farago

Received: 2020.02.23; Accepted: 2020.12.18.

*Corresponding author: vghorbanzadeh@gmail.com; ghorbanzadeh.vajiheh@lums.ac.ir; (V.G.).

\section{HIGHLIGHTS}

- Testosterone decrease pancreas p53 expression levels in type 2 diabetes and castrated diabetic rats.

- Voluntary exercise decrease pancreas p53 expression levels in type 2 diabetes and castrated diabetic rats.

- Testosterone combined with Voluntary exercise had a synergistic effect on reducing pancreas p53 expression levels and decrease the symptoms of type 2 diabetes in diabetic and castrated diabetic rats.

Abstract: Increased apoptosis in the pancreas and beta cell death causes reduced insulin secretion in type 2 diabetes. This study was aimed to evaluate the effects of exercise training and testosterone administration on apoptosis marker (p53 protein) in the pancreas tissue in animal with diabetes. Type 2 diabetes was induced by high fat diet and injection of low dose STZ (35 mg/kg; ip). After 2 months of treatment with testosterone $(2 \mathrm{mg} / \mathrm{kg} /$ day) or voluntary exercise alone or in combination, apoptosis (tunnel assay) and p53 protein (ELISA method) were measured. Testosterone and exercise decreased the blood glucose, HbA1c levels, HOMA-IR, p53 protein expression and increased insulin level in treated diabetic and diabetic castrated groups. Simultaneous treatment of these groups with testosterone together voluntary exercise had an additive effect on reducing p53 expression, blood glucose, HbA1c levels, HOMA-IR and subsequently 
decreasing apoptosis. Our results suggest that the apoptosis decreasing effect of testosterone and voluntary exercise is associated with the reduced levels of blood glucose, HbA1c and HOMA-IR that subsequently decreased the expression of p53 level.

Keywords: testosterone; voluntary exercise; apoptosis; p53; diabetic castrated rats.

\section{INTRODUCTION}

Type2 diabetes is regarded as a heterogeneous condition due to identification of defects of $\beta$-cell function and insulin resistance [1]. As beta-cell function progressively declines linearly with time, hyperglycemia occurs and $50 \%$ of individuals require insulin therapy [2]. Decreased $\beta$ - cell mass following with impaired $\beta$ cell function is the main problem in type 2 diabetes and normalization of beta cell function have been investigated intensely [3-5]. Since the apoptosis is the major cause of decreased $\beta$ cells in type 2 diabetes [6], therapeutic approaches designed to target anti apoptotic factor such as p53 could be an important achievement for the treatment of type 2 diabetes.

Testosterone not only plays a key role in the development of male reproductive but also involves in metabolic disease [7]. There is an inverse relationship between testosterone and insulin concentration so that low testosterone levels causes insulin resistance and type 2 diabetes [8,9]. It was indicated that castration causes pancreas apoptosis that adversely affects insulin secretion [10]. Both animal and clinical studies indicate that testosterone replacement therapy can improve ratio of apoptotic cells in the pancreas tissue by improvement glycaemic control and reducing inflammatory factors in type 2 diabetes $[11,12]$.

Regular exercise is an integral component of the lifestyle management to prevent or delay type 2 diabetes development [13]. In diabetic animals, exercise improves blood glucose control and reduces $\beta$-cell damage and increases total insulin content [14]. Antiapoptotic effect of exercise in several tissues and experimental models via modulation of intracellular pathways was reported [15-17]. Paula and coauthors indicated that exercise training protects human and rodent $\beta$-cells against endoplasmic reticulum stress and apoptosis in both type 1 and 2 diabetes [18]. Another experiment demonstrated that exercise protect $\beta$-cells from death in a diabetic condition through inflammatory factors [19]. However, it is known that exercise protects $\beta$-cells against diabetes development but it is not clear how execrcise enhance the $\beta$-cells viability and whether factors released during exercise training contribute to the reducing the $\beta$-cells apoptosis.

Overall, though, data on the effects of testosterone therapy combined with voluntary exercise on pancreas apoptosis and associated effects on p53 protein in high fat diet-streptozotocin type 2 diabetic rats remain limited.

\section{MATERIAL AND METHODS}

\section{Animals}

Sixty-three adult male wistar rats (200-250 g) from the Tabriz medical faculty (Iran-Tabriz), were housed at $22 \pm 2{ }^{\circ} \mathrm{C}$ on a 12-h light-dark cycle with free access to food and water in the department's animal facilities. The rats were maintained in collective cages ( 5 per cage) while animals in the exercise group were placed in individual wheel-cage units. All the experiments in this study were approved by the Institutional Animal Ethics Committee of Tabriz Medical University.

\section{Experimental design}

For induction of type 2 diabetes, sixty-three rats were fed with high-fat diet comprising $22 \%$ fat, carbohydrate $48 \%$ and protein $20 \%$ in blend with standard laboratory chow consisting of $5 \%$ fat, $53 \%$ carbohydrate and $23 \%$ protein for 4 weeks. Then, animals were injected with streptozotocin (STZ) (SigmaAldrich, Oakville, ON, Canada) at low dose (35 mg/kg; ip). Three days after STZ injection, fasting blood sugar and insulin levels were measured. Rats with a fasting blood glucose of $\geq 300 \mathrm{mg} / \mathrm{dl}$ were considered type 2 diabetes. After model confirmation by glucose tolerance test and insulin measurement in comparison with normal chow-fed, rats in castrated groups were anesthetized with ketamine/xylazine $(88 / 10 \mathrm{mg} / \mathrm{kg}$,i.p.) or in the sham-operation, the same procedure was followed without removal of the testes [19-21].

Diabetic rats were randomly assigned to 9 groups with seven animals in each group, receiving the following treatment for 60 consecutive days.

Group I- sham, the operated diabetic rats were received placebo.

Group II- diabetic rats (Dia), diabetic rats were received placebo. 
Group III-diabetic rats were received testosterone (2 mg/kg/day) (Tes).

Group IV-diabetic rats were performed exercise (Exe).

Group V-diabetic rats were received testosterone $(2 \mathrm{mg} / \mathrm{kg} /$ day) and performed exercise (Tes-Exe).

Group VI-castrated diabetic rats were received placebo (Cas).

Group VII-castrated diabetic rats were received testosterone (2 mg/kg/day) (Cas-Tes).

Group VIII-castrated diabetic rats were performed exercise (Cas- Exe).

Group IX-castrated diabetic rats were received testosterone $(2 \mathrm{mg} / \mathrm{kg} / \mathrm{day})$ and performed exercise (Cas-

Tes-Exe).

For testosterone replacement, rats received testosterone propionate (UNIGEN Life Science) at a physiologic dose (2 mg/kg/day) dissolved in dimethyl sulfoxide (DMSO) once daily for 8 weeks [22]. Rats in placebo groups received DMSO vehicle with the same amount. Each exercising animal was placed individually in cages containing a steel running wheel. Each wheel was connected to digital magnetic counter to measure running activity. Based on previous experience rats with running distance lower than $2 \mathrm{~km}$ day-1 as the minimal average running activity were eliminated before statistical analysis [23]. The body weight of all rats was measured at week 0 and after 8 weeks treatment.

\section{Oral glucose tolerance test (OGTT) and insulin resistance}

After $12 \mathrm{~h}$ fasting, the oral glucose tolerance test (OGTT) was performed at $0,30,60,90,120$ min by feeding glucose $1.0 \mathrm{~g} / \mathrm{kg}$ body weight through gavages. Before administration of glucose solution, blood was drawn from the inferior vena cava vein for plasma glucose and insulin concentrations measurements. Insulin concentration was measured by enzyme-linked immunosorbent assay (ELISA) using commercial rat-specific ELISA kits (Cat. No. KA3811, Abnova, Germany) according to the manufacturer's protocol. Insulin resistance was assessed by using Homeostasis Model Assessment of Insulin Resistance (HOMA-IR) and Quantitative Insulin Sensitivity Check Index (QUICKI). HOMA-IR index was calculated according to the formula: [-fasting glucose $(\mathrm{mg} / \mathrm{dL}) \times$ fasting insulin $(\mathrm{mU} / \mathrm{mL})] / 405$. QUICKI was estimated according to the formula: $1 \neg /[\log$ fasting insulin $(\mathrm{mU} / \mathrm{mL})+$ log fasting glucose $(\mathrm{mg} / \mathrm{dL})][24,25]$.

\section{Pancreas tissue preparation}

On the last day of the experiment the rats were anesthetized with ketamine/xylazine $(88 / 10 \mathrm{mg} / \mathrm{kg}$, i.p.). Blood samples were collected from aorta to measurement blood glucose concentration, insulin levels and Hemoglobin A1c (HbA1c) determination. HbA1c was determined by immunoturbidimetric assay [26]. Pancreas tissue was quickly removed from the sacrificed rat, washed with saline $0.9 \%$. Then pancreas was excised, frozen in liquid nitrogen and stored at deep freeze $\left(-70^{\circ} \mathrm{C}\right)$ for p53 protein measurements.

\section{Measurement of pancreatic apoptosis marker}

For the detection of p53 protein (apoptosis marker), we used a p53 pan ELISA kit (Roche Molecular Biochemicals, Mannheim, Germany). This assay for the quantification of wild-type and mutant p53 of human, mouse, and rat origin, is based on a quantitative sandwich ELISA principle. The biotin labeled capture antibody is pre-bound to the streptavidin-coated micro titer plate. During a single incubation step, the p53 containing sample reacts with the capture antibody and the peroxidase labeled detection antibody to form a stable immune complex. Subsequent to the washing step, the peroxidase bound in the complex is developed by tetramethylbenzidine as a substrate. The resultant absorbance is proportional to the concentration of p53. Tissue homogenates were prepared from tissues, as described in the p53 pan ELISA kit and collected supernatants were analyzed according to the manufacturer's instructions [26].

\section{Apoptosis by TUNEL assay}

To investigate cell apoptosis in pancreatic tissue sections, a TUNEL assay was performed with the in Situ Cell Death Detection Kit (Rosch Molecular Chemical, Germany) according to the manufacturer's instructions. Briefly, the sections were digested with proteinase $\mathrm{K}(20 \mathrm{lg} / \mathrm{mL})$ and kept for $15 \mathrm{~min}$ at room temperature and then washed by $2 \% \mathrm{H}_{2} \mathrm{O}_{2}$ for $5 \mathrm{~min}$ at room temperature. Sections incubated with terminal deoxynucleotidyl transferase (TdT), digoxigenin nucleotide and unlabeled nucleotide for $1 \mathrm{~h}$ in a humidified chamber at $37^{\circ} \mathrm{C}$. Antidigoxigenin conjugate was applied directly to the slides for $30 \mathrm{~min}$ at room temperature. Slides were washed in PBS and exposed DAB for $5 \mathrm{~min}$. The slides were then rinsed in water and mounted. Apoptotic cells were identified by a brown stain over the nuclei [27]. 
Apoptotic index $(\mathrm{Al})=($ number of labeled cells $/$ total number of cells counted $) \times 100$

\section{Statistical analysis}

Data were expressed as mean \pm SD for seven animals for quantitative variables and statistically analyzed by using SPSS program (version 18 for windows). Differences between groups were assessed by two-way analysis of variance (ANOVA) followed by Tukey's test. Repeated measures ANOVA models were used to analyze the glucose mean response profiles over the 5 -time point $2 \mathrm{~h}$ OGTT. $\mathrm{P}$ values of less than 0.05 were considered statistically significant $(p<0.05)$.

\section{RESULTS}

\section{Changes of body weight}

The mean body weight of animals in experimental groups is shown in Table 1. The present study showed that STZ injection with low dose $(35 \mathrm{mg} / \mathrm{kg}$ ) decreased the body weight in all groups. Moreover, it was found that administration of testosterone and voluntary exercise to the diabetic and diabetic castrated groups resulted in an increase in the body weight in comparison to Dia and Dia-Cas groups before treatments but this increase is not significant (1-A and 1-B). In addition, it was observed that administration of testosterone together voluntary exercise to the diabetic and diabetic castrated groups significantly $(p<0.05)$ increased in the body weight in comparison to Dia and Dia-Cas groups. Table 1 shows the change in body weight in rats after treatment with testosterone and voluntary exercise. Testosterone combined with voluntary exercisetreated rats experienced significant weight gain as compared with Dia and Dia-Cas groups $(\mathrm{p}<0.05)$. No significant difference was detected between sham and diabetic groups (data are not shown).

\section{Serum glucose, insulin concentration, HOMA-IR and QUICKI}

After 8 wks. of intervention, glucose levels decreased in the Dia-E and Dia-T groups compared with Dia $(p<0.05$ and $p<0.01$ respectively). Also, in combination groups with testosterone and exercise, there is a significant difference in blood glucose as compared with Dia group $(p<0.001)$. In Dia-E and Dia-T-E groups, insulin levels were higher than Dia group $(p<0.05)$ (Table 2-A, Figure 1A). Although, insulin did not change significantly in Dia-T-E compared with Dia-E, the calculated HOMA-IR was significantly decreased in the diabetic rats administration with testosterone together exercise compared to Dia-T and Dia-E groups after 60 days of treatments. In castrated rats there was a significant difference in insulin concentration and glucose levels between treatments groups with Dia-Cas $(p<0.001)$. Also, we also observed the decreasing level of blood glucose, HOMA-IR index and increasing concertation of insulin in combination group of testosterone and voluntary exercise compared with Dia-Cas (Table 2-B, Figure 1B). Glucose level was lower in Dia-CasT-E group than Dia-Cas-E and Dia-Cas-T groups ( $p<0.05$ and $p<0.01$ respectively) (Table 2-B). Compared to each treatment alone, combination- treated castrated rats had higher insulin and lower HOMA-IR as measured at the end of the study (Table 2-B). While, QUICKI was not significantly changed in all groups. No significant difference was detected between sham and diabetic groups (data are not shown).

\section{Effect of testosterone and voluntary exercise on glycosylated HbA1c levels}

Figure $2 \mathrm{~A}$ shows that the blood $\mathrm{HbA} 1 \mathrm{c}$ level of the treatment groups was significantly different from the blood $\mathrm{HbA} 1 \mathrm{c}$ level of the Dia group $(\mathrm{p}<0.05$ and $\mathrm{p}<0.001)$. HbA1c level in the diabetic rats was significantly $(p<0.01)$ lower than that in the Dia-T and Dia-E groups after the treatment with both interventions of testosterone and voluntary exercise. Also, testosterone replacement and voluntary exercise performing improved HbA1c level of castrated rats (Figure 2B). In Dia-Cas-T-E group, eight weeks combination therapy with testosterone and exercise significantly reduces $\mathrm{HbA} 1 \mathrm{c}$ level in the pancreas tissue in comparison with Dia-Cas-T and Dia-Cas-E groups ( $p<0.5$ and $p<0.01$ respectively).

\section{Oral glucose tolerance test (OGTT)}

Curves for glucose concentrations during the OGTT are shown in Figure 3A and 3B. Blood glucose in all diabetic groups except Dia-Cas group were significantly $(p<0.001)$ lower than that of Dia groups in time 0 (Figure 3A). In treatment diabetic rats, the significant differences were detected in Dia-T, Dia-T-E and DiaCas-T-E groups after $30 \mathrm{~min}$ as compared with diabetic rat (Dia-T and Dia-T-E $p<0.001$, Dia-Cas-T-E $\mathrm{p}<0.01)$. At 30 mins, serum glucose levels in all casterated diabetic rats treatment with testosterone and 
exercise significantly lower than Dia-Cas (Dia-Cas-E $p<0.05$, Dia-Cas-T $p<0.01$ and Dia-Cas-T-E $p<0.001$ ). After $1 \mathrm{~h}$ of glucose load, serum glucose levels in Dia-T-E, Dia-Cas-T-E and Dia-Cas groups were significantly different of Dia group $(\mathrm{p}<0.001)$. In castrated diabetic rats, at 60 mins after glucose challenge in an oral glucose tolerance test, there was a significant difference in treatment groups in comparison to Dia-Cas group $(p<0.001)$. At time of 90 , glucose level in treatment diabetic rats and Dia-Cas-T-E group was lower than Dia group (Dia-T $p<0.05$, Dia-E $p<0.05$, Dia-T-E $p<0.001$ and Dia-Cas-T-E $p<0.001$ ). Also, in castrated diabetic rats the serom glucose level in treatment groups were significantly lower than Dia-Ca group $(p<0.001)$. After $2 \mathrm{~h}$ of glucose load, testosterone administration and exercise performing producing low glucose level in diabetic treatment groups and Dia-Cas-E and Dia-Cas-T-E groups compared with Dia group $(p<0.001)$. Also, there was a significant difference between Dia-Cas-E and Dia-Cas-T-E groups with Dia-Cas group $(p<0.001)$.

\section{Effects of testosterone and voluntary exercise treatment on p53 and apoptosis index}

As seen in Figure 4A and 4B, ELISA analysis showed that testosterone and exercise significantly decreased the protein level in treatment groups compared with Dia group $(p<0.05)$. The p53 protein level markedly decreased by testosterone combined with exercise in comparison to Dia-T and Dia-E groups $(p<0.01)$. In castrated diabetic rats, there is a significance difference between treatment groups and Dia-Cas group $(p<0.01)$. The p53 level significantly decreased in the Dia-Cas-T-E group than in the Dia-Cas-T and Dia-Cas-E groups $(p<0.01)$.

\section{TUNEL analysis of pancreas sections from diabetic and diabetic castrated Rats}

The pancreas apoptosis index was evaluated using TUNEL staining (Figure 5A, 5B and Figure 6). Apoptosis index significantly decreased in Dia-T and Dia-E groups compared with Dia group $(p<0.01)$, while it was significantly increased in Dia-Cas group than in the Dia group $(p<0.01)$. Compared with Dia-T and Dia$E$ groups, the apoptosis index was significantly decreased in theDia-T-E group $(p<0.05)$. There was a significance difference between treatment groups and Dia-Cas group $(p<0.01$ and $p<0.001)$. The apoptosis index was lower in Dia-Cas-T-E group than in Dia-Cas-T $(p<0.01)$ and Dia-Cas-E $(p<0.05)$ groups.

Table 1. Effect of exercise and testosterone on body weight in diabetic (1-A) and castrated diabetic rats (1-B).

1-A

\begin{tabular}{lccc}
\hline Groups & Body weight (before) (gr) & Body weight (after) (gr) & Change in body weight ( \%) \\
\hline Dia & $250 \pm 9.3$ & $223 \pm 4.5$ & $-13.2 \pm 2.8$ \\
Dia- T & $245 \pm 5.8$ & $228 \pm 2.2$ & $-8.53 \pm 1.9$ \\
Dia-E & $253 \pm 6.2$ & $234 \pm 2.8$ & $-7.58 \pm 1.53$ \\
Dia-T-E & $257 \pm 5.5$ & $242 \pm 1.6^{*}$ & $-6.4 \pm 3.40^{*}$ \\
\hline
\end{tabular}

1-B

\begin{tabular}{llll}
\hline Groups & Body weight (before) (gr) & Body weight (after) (gr) & Change in body weight (\%) \\
\hline Dia & $250 \pm 9.3$ & $223 \pm 4.5$ & $-13.2 \pm 2.8$ \\
Dia-Cas & $251 \pm 3.8$ & $215 \pm 8.3$ & $-15 \pm 2.20$ \\
Dia-Cas-T & $255 \pm 8.9$ & $222 \pm 5.9$ & $-13 \pm 6.4$ \\
Dia-Cas-E & $250 \pm 6.6$ & $222 \pm 3.3$ & $-12 \pm 7.7$ \\
Dia-Cas-T-E & $253 \pm 7.5$ & $233 \pm 4.5^{+}$ & $-9.44 \pm 2.9^{+}$ \\
\hline
\end{tabular}

Body weight (before) indicates weights of animals that received high-fat and immediately after STZ injection. Body weight (after) indicates weights after treatment with testosterone and voluntary exercise. Change in body weight indicates percent of change in body weights after treatment with testosterone and voluntary exercise. Data are presented as mean \pm SD for 7 animals. ${ }^{*} p<0.05$ vs. the Dia group. $+p<0.05$ vs. the Dia-Cas group. 
Table 2. Effect of exercise and testosterone on blood glucose, serum insulin levels, HOMA-IR, and QUICKI in diabetic $(2-\mathrm{A})$ and castrated diabetic (2-B) rats.

2-A

\begin{tabular}{cccc}
\hline Groups & Insulin $(\boldsymbol{\mu} / \mathrm{l})$ & HOMA-IR & QUICKI \\
\hline Dia & $4.08 \pm 0.3$ & $5.2 \pm 0.1$ & $0.30 \pm 0.008$ \\
Dia- T & $4.8 \pm 0.4$ & $4.5 \pm 0.9^{*}$ & $0.27 \pm 0.002$ \\
Dia-E & $5.06 \pm 0.5^{*}$ & $4.8 \pm 0.9^{*}$ & $0.32 \pm 0.009$ \\
Dia-T-E & $5.5 \pm 0.3^{*}+$ & $3.5 \pm 0.4^{* *}+@$ & $0.32 \pm 0.005$ \\
\hline
\end{tabular}

2-B

\begin{tabular}{lccc}
\hline Groups & Insulin $(\mu / \mathrm{I})$ & HOMA-IR & QUICKI \\
\hline Dia & $4.08 \pm 0.3$ & $5.2 \pm 0.1$ & $0.30 \pm 0.008$ \\
Dia-Cas & $3.50 \pm 0.5$ & $5.9 \pm 0.5^{*}$ & $0.25 \pm 0.004$ \\
Dia- Cas-E & $4.5 \pm 0.3^{\#}$ & $5.1 \pm 0.3^{\#}$ & $0.30 \pm 0.003$ \\
Dia-Cas -T & $4.4 \pm 0.2^{\#}$ & $4.6 \pm 0.4^{\# \#}$ & $0.31 \pm 0.008$ \\
Dia-Cas-T-E & $5.3 \pm 0.5^{\star \# \# \times \$}$ & $3.9 \pm 0.1^{* * \times \times \times \$ \$}$ & $0.33 \pm 0.003$
\end{tabular}

All results were expressed as the mean \pm SD. ${ }^{*} p<0.05$ and ${ }^{* *} p<0.01$ vs. the Dia group. $+p<0.05$ vs. the Dia-T group. $@ p<0.05$ vs. the Dia-E group. \#p $<0.05$, \#\#p<0.01 vs. the Dia-Cas group. $X p<0.05, X X X p<0.001$ vs. the Dia-Cas-E group. $\$ p<0.05$ and $\$ \$ \$ p<0.001$ vs. the Dia-Cas- T group.

$A$

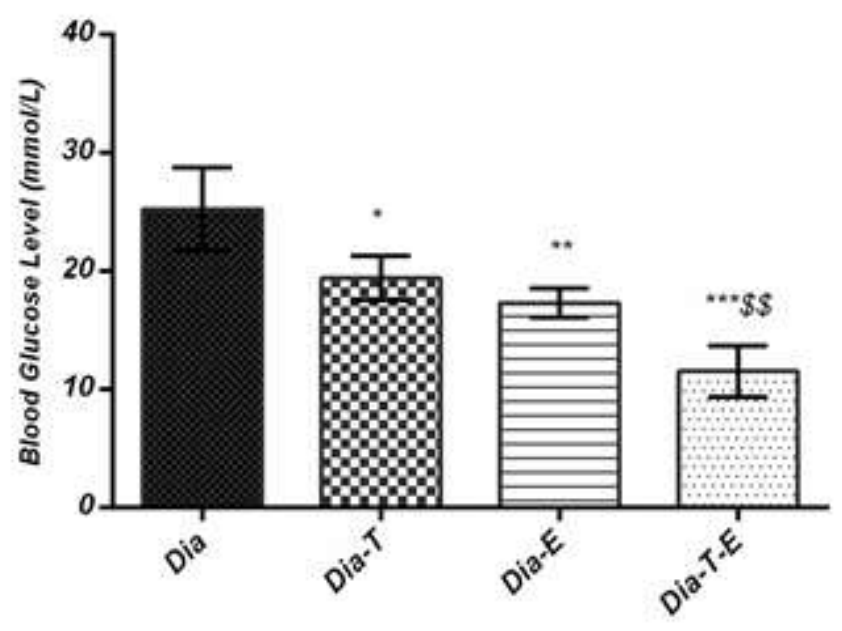

B

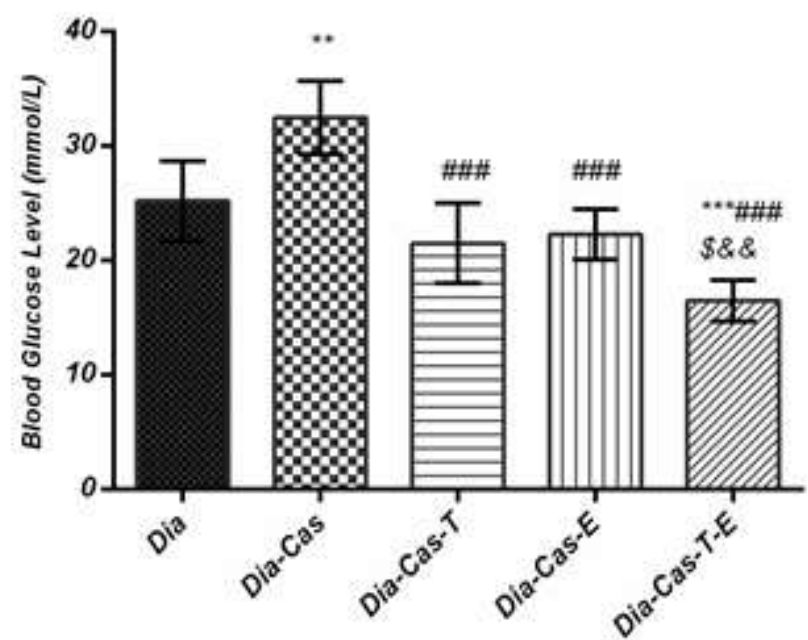

Figure 1. All results were expressed as the mean \pm SD. A: Effect of testosterone and voluntary exercise on glucose levels in diabetic rats. B: Effect of testosterone and voluntary exercise on glucose levels in castrated diabetic rats. ${ }^{*} p<0.05,{ }^{* *} p<0.01$ and ${ }^{* * *} p<0.001$ vs. the Dia group. $\$ \$ p<0.05$ vs. the Dia-T and Dia-E group. \#\#\#p<0.001 vs. the DiaCas group. \&\&p<0.01 vs. the Dia-Cas-E group. $\$ p<0.05$ vs. the Dia-Cas- T group. 
$A$

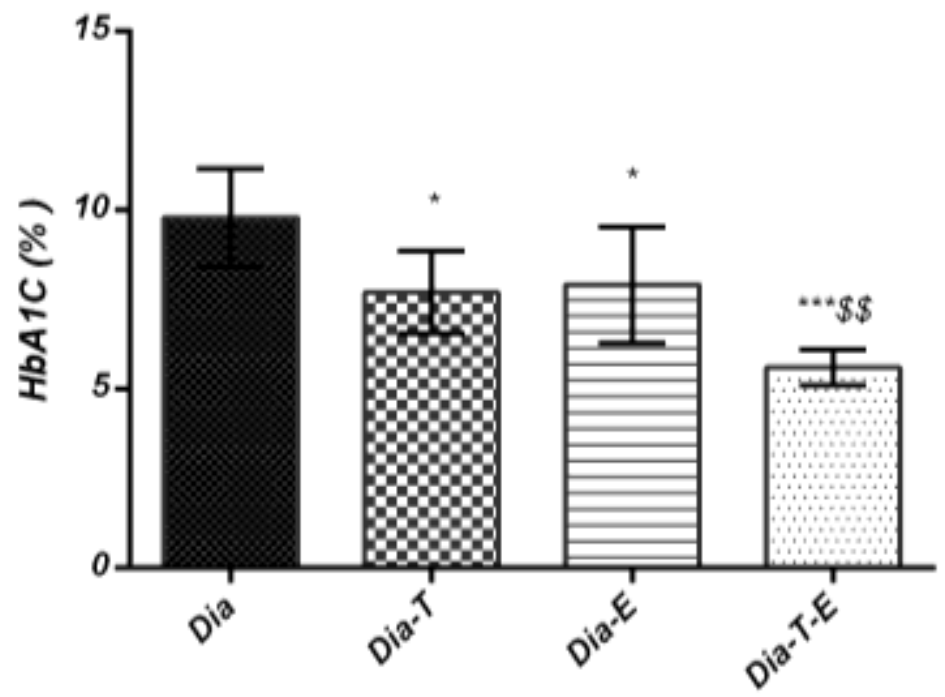

B

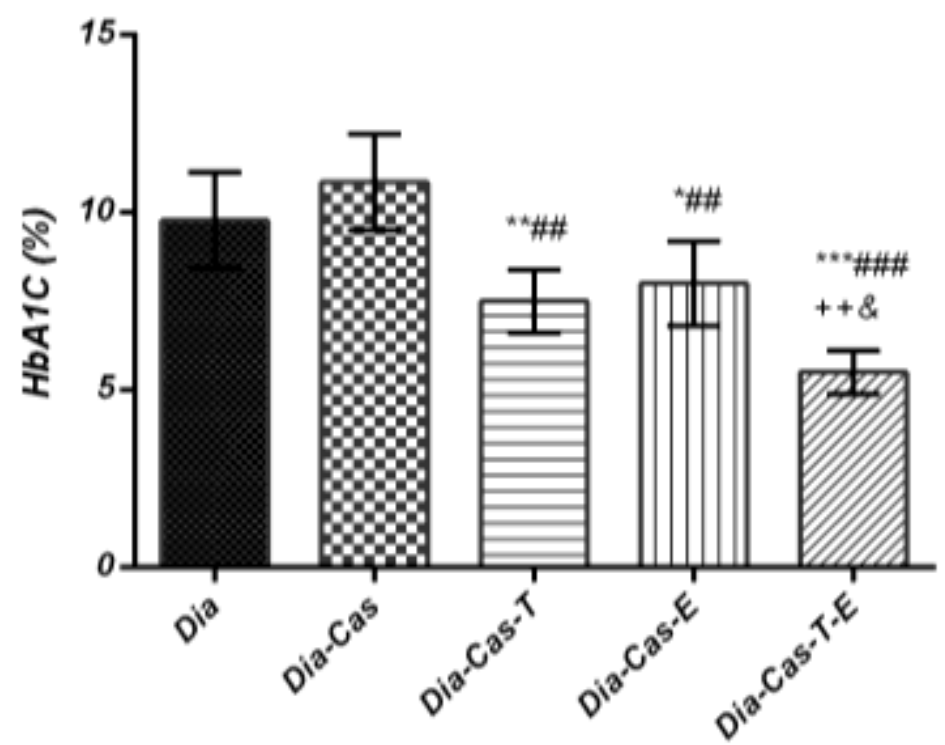

Figure 2. All results were expressed as the mean $\pm \mathrm{SD}$. A: Effect of testosterone and voluntary exercise on $\mathrm{HbA} 1 \mathrm{c}$ levels in diabetic rats. B: Effect of testosterone and voluntary exercise on $\mathrm{HbA} 1 \mathrm{c}$ levels in castrated diabetic rats. ${ }^{*} p<0.05,{ }^{* *} p<0.01$ and ${ }^{* * *} p<0.001$ vs. the Dia group. $\$ \$ p<0.01$ vs. the Dia-T and Dia-E groups. \#\#p<0.01 and \#\#\# $p<0.001$ vs. the Dia-Cas group. $++p<0.01$ vs. the Dia-Cas-E group. $\& p<0.05$ vs. the Dia-Cas- T group. 


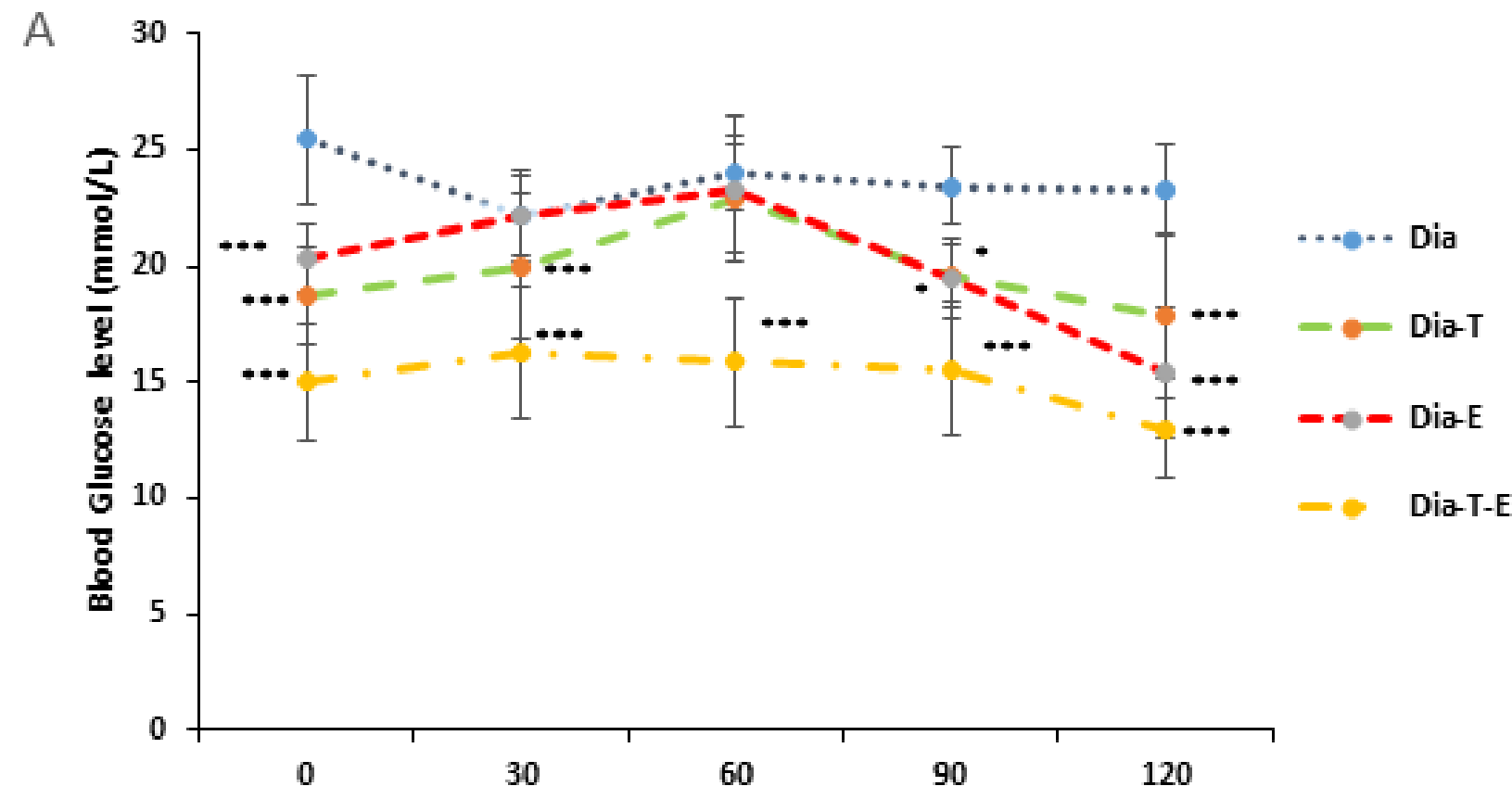

Time

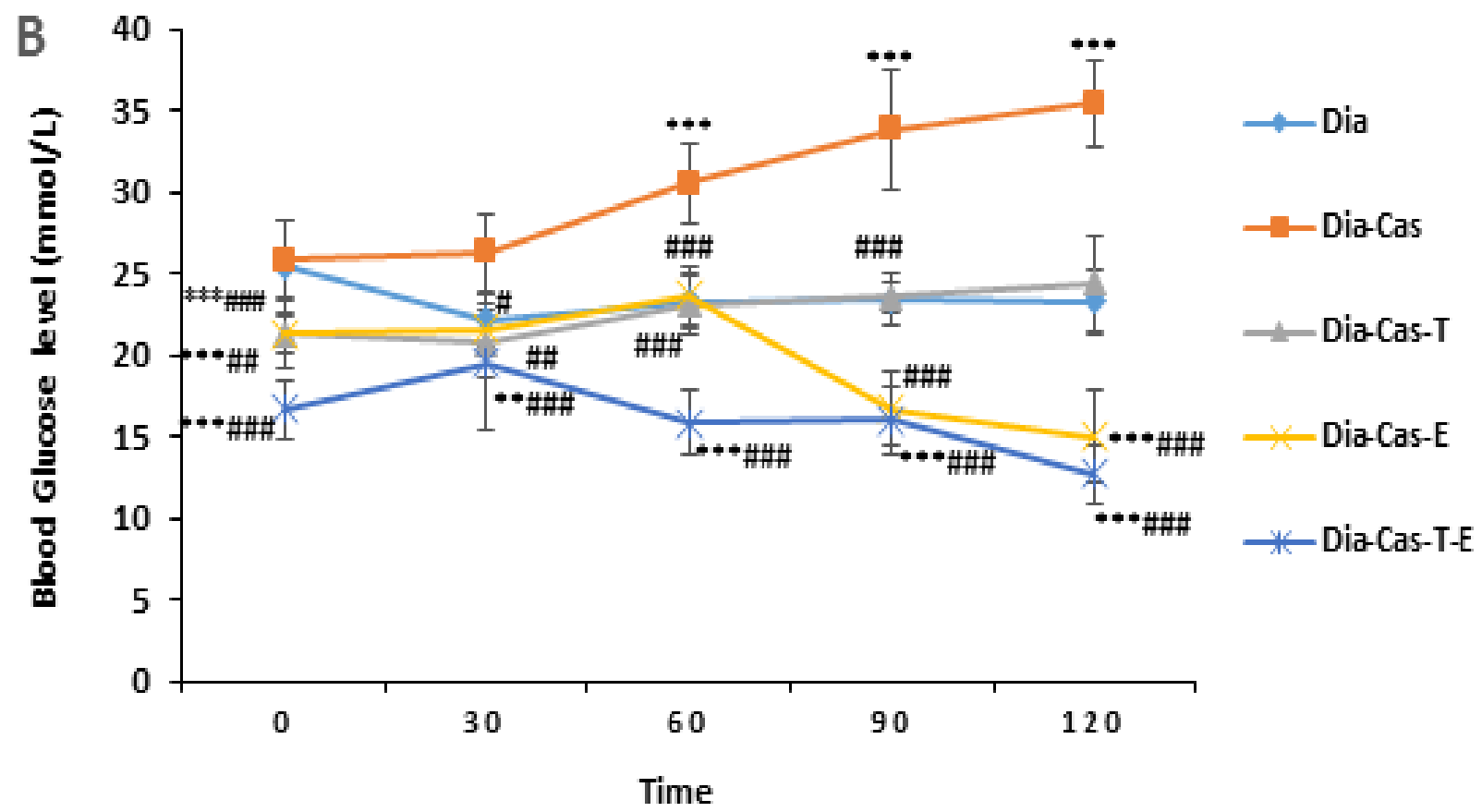

Figure 3. All results were expressed as the mean \pm SD. A: Effect of testosterone and voluntary exercise on OGTT in diabetic rats. B: Effect of testosterone and voluntary exercise on OGTT in castrated diabetic rats. ${ }^{*} p<0.05$ and ${ }^{* * *} p<0.001$ vs. the Dia group. $\# p<0.05, \# \# p<0.01$ and \#\#\# $p<0.001$ vs. the Dia-Cas group. 
A

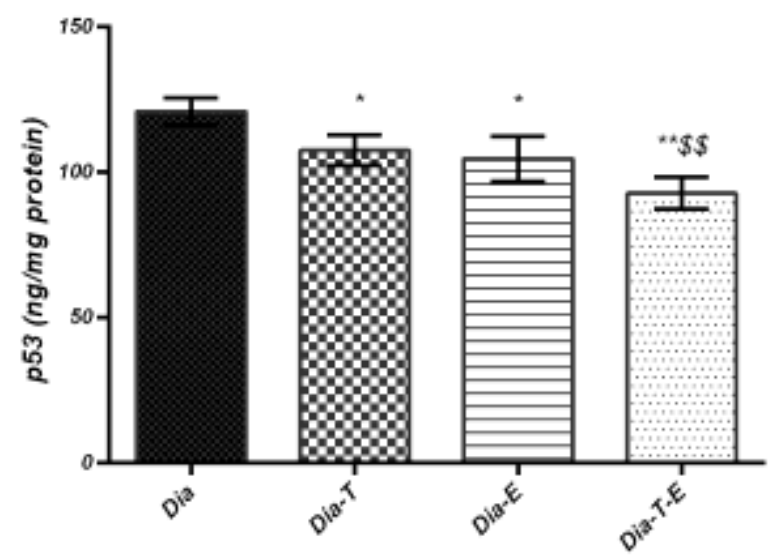

B

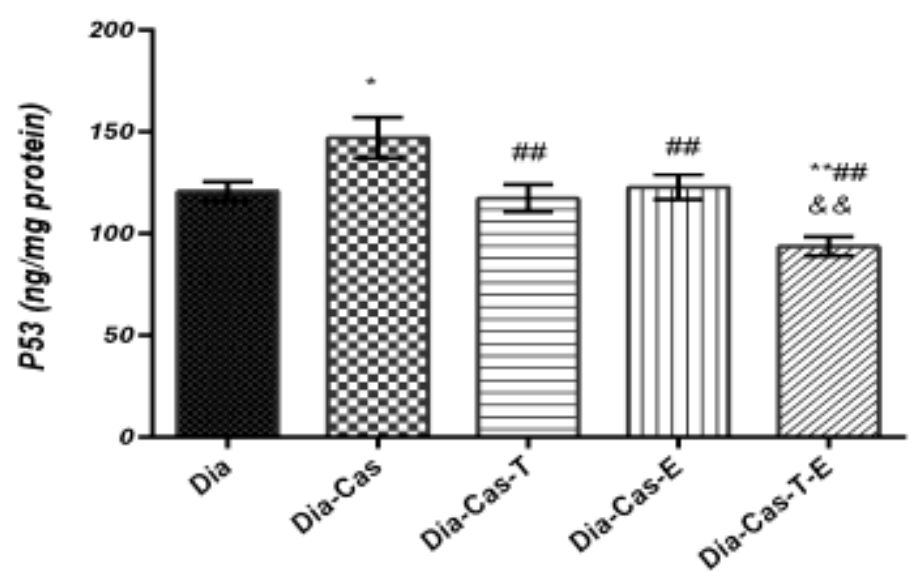

Figure 4. All results were expressed as the mean \pm SD. A: Effect of testosterone and voluntary exercise on p53 levels in diabetic rats. B: Effect of testosterone and voluntary exercise on $p 53$ levels in castrated diabetic rats. ${ }^{*} p<0.05$, ${ }^{* *} p<0.01$ vs. the Dia group. $\$ \$ p<0.01$ vs. the Dia-T and Dia-E groups. \#\#p<0.01 vs. the Dia-Cas group. \&\&p<0.01 vs. the Dia-Cas-E and Dia-Cas- T groups.

A

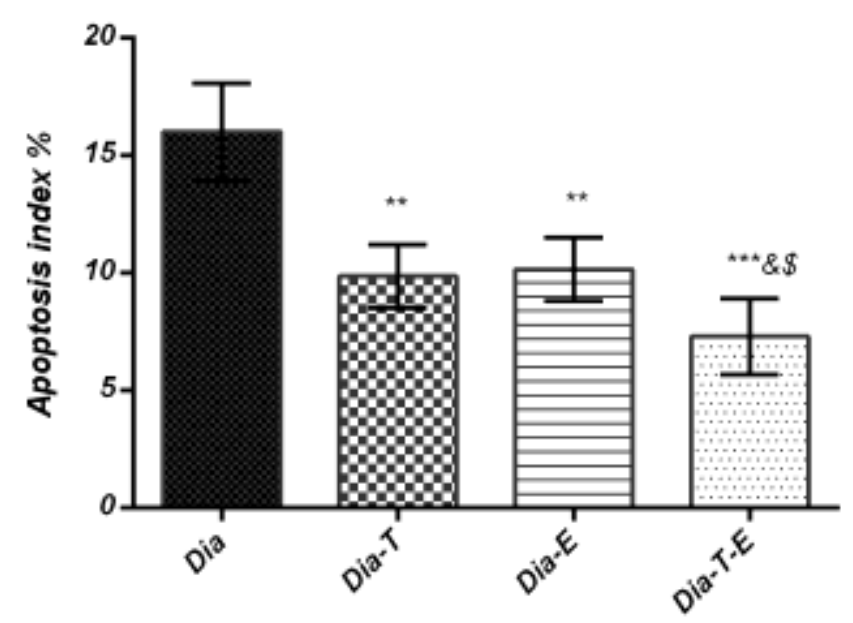

B

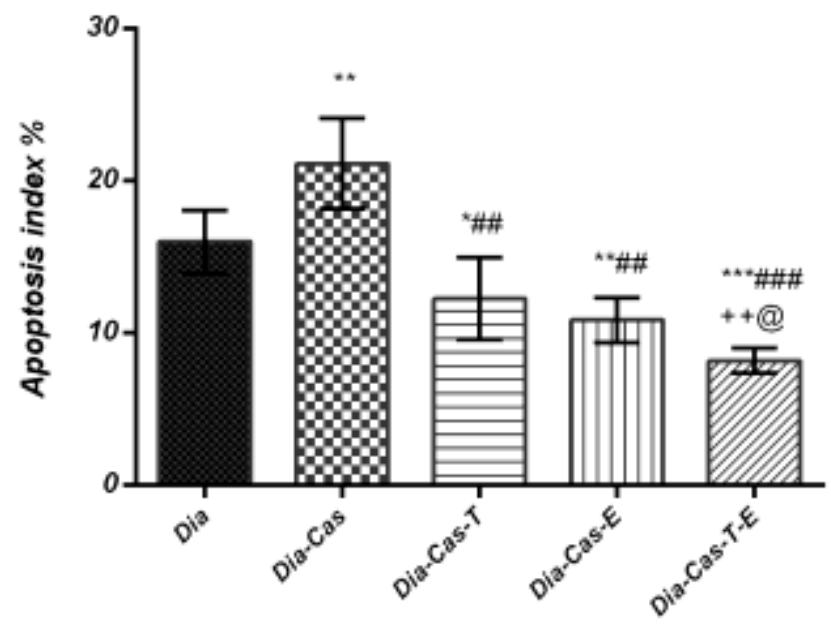

Figure 5. All results were expressed as the mean \pm SD. A: Effect of testosterone and voluntary exercise on apoptosis index in diabetic rats. B: Effect of testosterone and voluntary exercise on apoptosis index in castrated diabetic rats. ${ }^{*} p<0.05$, ${ }^{* *} p<0.01$ and ${ }^{* * *} p<0.001$ vs. the Dia group. $\$ p<0.05$ vs. the Dia-T group. \& $p<0.05$ vs. the Dia-E group. $\# \# p<0.01$ and $\# \# \# p<0.001$ vs. the Dia-Cas group. $++p<0.01$ vs. the Dia-Cas-T group. @p $<0.05$ vs. the Dia-Cas- $E$ group. 

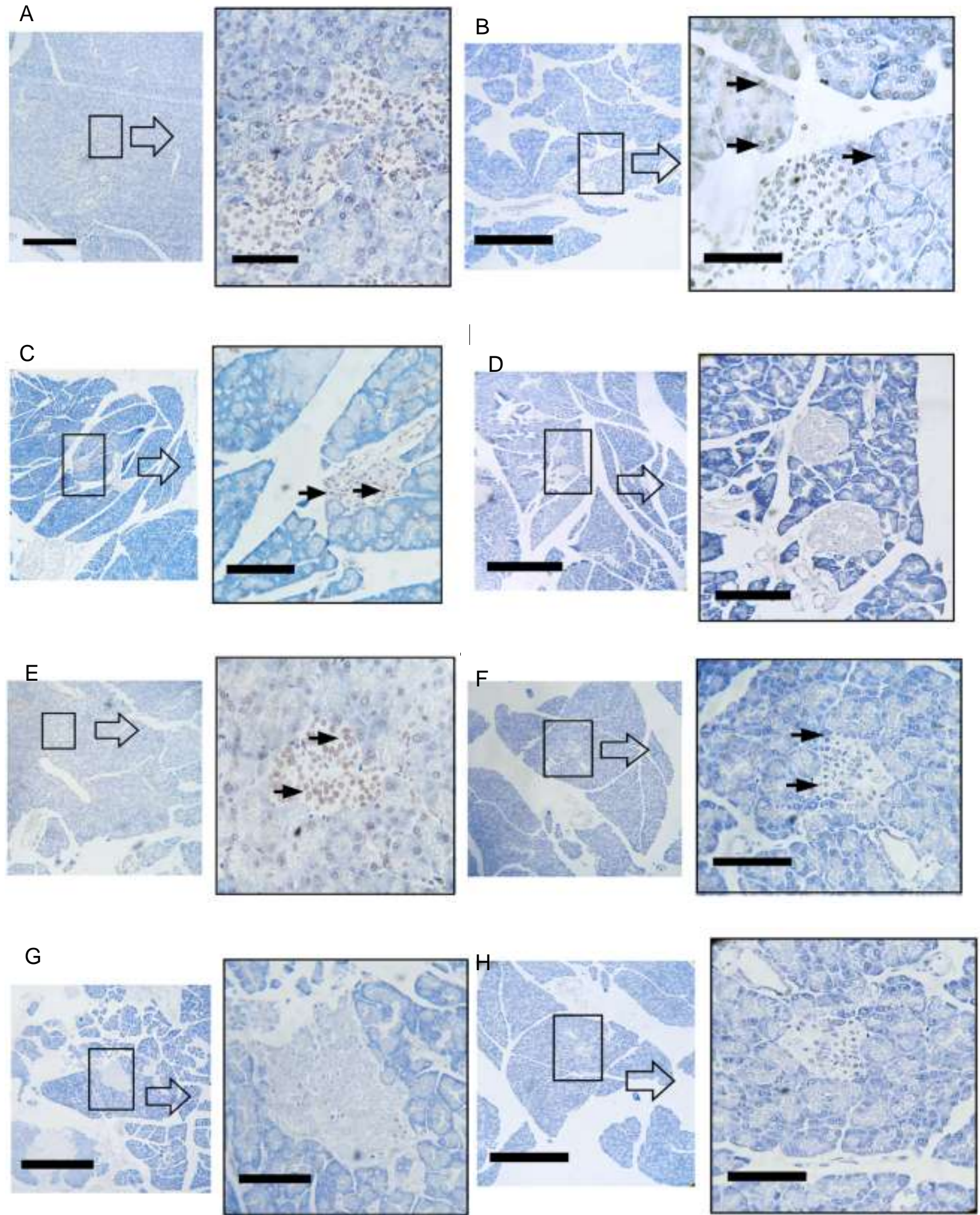

Figure 6. Effect of testosterone and voluntary exercise on apoptosis that stained by the TUNNEL method in diabetic and castrated diabetic. A: Dia, B: Dia-T, C: Dia-E, D: Dia-T-E, E: Dia-Cas, F: Dia-Cas-T, G: Dia-Cas-E, H: Dia-Cas-TE. 


\section{DISCUSSION}

The present study discussed about the anti-apoptotic effect of testosterone and voluntary exercise in experimental T2DM rats induced by high-fat diet combined with low-dose STZ. This study has shown that testosterone and voluntary exercise improved hyperglycemia, $\mathrm{HbA} 1 \mathrm{c}$ and insulin resistance in diabetic and castrated rats support previous findings $[28,29]$, but had no effect on insulin sensitivity in both groups of animals (diabetic and castrated rats). Also, results demonstrated that these treatments significantly increased blood insulin levels and p53 protein of pancreases tissue in diabetic and castrated diabetic rats.

$\beta$-cell apoptosis in pancreas tissue is a characteristic feature of type 2 diabetes. Therefore, improvement of $\beta$-cell apoptosis is an important therapeutic goal. In this study we injected STZ at low dose to high fat diet rats to induce apoptosis in islet cell that leading to high level of blood glucose and low production of insulin, which were similar to those found in diabetic humans [30]. However, the precise mechanisms responsible for this defect remain unknown. In this study we examined the effect of testosterone and voluntary exercise on $\beta$-cell apoptosis in diabetic and diabetic castrated rats.

Testosterone, an anabolic steroid, plays an important role in the metabolic activity in glucose regulatory tissues [31]. Therefore, experimental or pathological manipulation of testosterone leading to change the metabolic activities of tissues [28]. In this study we observed that testosterone replacement increased serum insulin level and decreased blood circulating glucose level. Muthusamy and coauthors suggested that normal level of testosterone is essential to maintain optimized insulin concentration in serum [28]. Holmang and coauthors demonstrated that testosterone administration caused hyperinsulinemia in female adult rats in both intact and ovariectomized animals [32]. Xia and coauthors also reported that testosterone deficiency is associated with increasing fasting blood glucose in male adult rats [33]. Grillo and coauthors have indicated that testosterone induces uptake of calcium and stimulates insulin secretion in isolated pancreatic islets [34]. In accordance with this, our results showed that serum insulin level following testosterone replacement was significantly increased and glucose level and $\mathrm{HbA} 1 \mathrm{c}$ reduced when compared to castrated rats. Therefore, when insulin rises following testosterone replacement therapy, insulin stimulates glucose transport in regulatory organ such as skeletal muscle and adipose tissue and leading to glucose reducing and $\mathrm{HbA} 1 \mathrm{c}$. Addition with this, several studies have indicated the relationship of serum testosterone with insulin levels using surrogate measures of insulin resistance such as for HOMA-IR and QUICKI. Saad and coauthors have reported that testosterone treatment resulted in a significant improvement in the HOMA-IR index in those patients with sexual dysfunction [35]. Groti and coauthors have demonstrated that testosterone therapy replacement resulted in reduction of HOMA-IR and HbA1c in obese hypogonadal men with type 2 diabetes [36]. We found that testosterone administration did not restore QUICKI in diabetic and diabetic castrated rats. In contrast, previous study found that testosterone replacement improved peripheral insulin sensitivity in hypogonadal men with type 2 diabetes [12]. The possible explanation of this controversy could be due to the different durations of testosterone replacement therapy and kind of experimental animals.

Moreover, the result of this study suggests that testosterone protects pancreas tissue function by decreasing proinflammatory cytokines cells from apoptosis, since the administration of testosterone significantly reduced the p53 protein and apoptotic index in the pancreas tissue of diabetic and castrated diabetic rats. It is clear that in the work, molecular and histological studies conducted on the pancreas tissue, but the results can be extended to langerhans islands and beta cells as well. In as much as, decreased apoptotic index obtained by the histopathological study and tunel assay confirmed the presence of apoptosis in the langerhans islets, given that $70 \%$ percent of islands are beta cells. Morimoto and coauthors have shown that early pancreases apoptotic damage produced by STZ in castrated rats was reversed by testosterone. These authors suggested that testosterone possess antioxidant and protective antiapoptotic effects in pancreases tissue [10]. Kapoor and coauthors have reported that testosterone treatment improves $\beta$-cell function by decreasing proinflammatory cytokines in hypogonadal men with type 2 diabetes [12]. Hanchang and coauthors indicated that testosterone protect $\beta$-cell against high-glucose induced apoptosis via decreased endoplasmic reticulum(ER) stress [37]. Also, Kooptiwut and coauthors reported that testosterone protects against high-glucose-induced b-cell apoptosis through the inhibition of ROS production both in vitro and ex vivo [38]. These results generally agree with our expected results that demonstrated testosterone protect pancreas tissue in castrated diabetic rats via suppression of apoptosis and its signaling pathway including p53 protein.

The main findings of this study were that voluntary exercise significantly decreased blood glucose level and $\mathrm{HbA} 1 \mathrm{c}$ in high fat diet fed-STZ induced type 2 diabetic rats. Biochemical analysis also revealed that voluntary exercise was able to significantly increase insulin content and tended to decrease HOMA-IR. Voluntary exercise dose not elevate stress hormone unlike forcible exercise and animals are permitted to 
exercise at the intensity, duration, and frequency patterns that they choose during their normal awake time at night [39]. Hyperglycemia in patients with type 2 diabetes impairs glucose-induced insulin secretion and insulin gene expression. Didek and coauthors demonstrated that obese rats that received swimming physical activity for ten days reduced the hyperglycemia and HOMA-IR index \{Didek, 2019 \#60\}. Miyazaki and coauthors suggested that hyperglycaemia produces reactive oxygen species that affect pancreas tissue function and increase insulin resistance which leads to the aggravation of type 2 diabetes [40]. Oliveira and coauthors showed that oxidative stress is the main biomarkers of risk factor for exacerbate the symptom of patients with type2 diabetes \{Oliveira, 2014 \#61\}. Pold and coauthors also showed that treadmill improved peripheral and hepatic insulin action and islet morphology [41]. Kiraly and coauthors reported that swimmingtrained diabetic rats did not develop hyperglycemia, which was associated with enhanced insulin secretion and increased $\beta$-cell proliferation that lead to improved islet morphology $[38,42]$. Park and coauthors showed that voluntary exercise improved systemic insulin sensitivity in ovariectomized rats fed high fat diet [43]. Since, voluntary exercise reduces blood glucose level and preserve GLUT-4 expression, a key regulator of carbohydrate and lipid metabolism, protection of $\beta$-cell from hyperglycemia damage and increasing secretion of insulin could be a possible mechanism by which voluntary exercise prevents progression of diabetes [43]. These previous reports support our findings. Our results demonstrated that body weight of diabetic rats and castrated diabetic rats in combined therapy groups was significantly lower than that of diabetic group without any intervention. In line with our results, Asikainen and coauthors showed that different protocols of exercise only produce a small decrease in body weight in menopausal women [44]. Chen and coauthors reported exercise training significantly reduced the body weight and suggested that body weight reduction may alleviate insulin resistance in ovariectomized rats [45]. The present data showed that voluntary exercise decrease p53 protein level, apoptosis biomarker, in the pancreas tissue of castrated diabetic rats. The involvement of hyperglycemia, p53 and mitochondrial pathway of apoptosis was widely investigated in pancreatic cells [46,47]. Pancreatic apoptosis is activated by hyperglycemia and involves ROS production, resulting in mitochondrial p53 mobilization followed by fragmentation of nuclear DNA [48]. Slentz and coauthors observed that both moderate- and vigorous-intensity exercise training improved $\beta$-cell function [49]. Shih and coauthors found significant increase in the disposition index after the 12-week training, suggesting an improvement pancreas tissue function [50]. Zhao and coauthors suggest that exercise improves diabetes symptoms via enhancement of the Langerhans islands mass and function through reducing $\beta$-cell apoptosis by activating Akt in obese OLETF rats [51]. Laker and coauthors concluded that early life exercise training in rats significant increases in $\beta$-cell mass and may have beneficial consequences for later metabolic health and disease [52]. In this study, we report that in type 2 diabetic castrated rats, combined therapy produced greater therapeutics effects than the individual treatments, it reduced blood glucose level, HbA1c, body weight, insulin resistance, p53 protein level and increased insulin secretion. Therefore, voluntary exercise in combination with testosterone reduced symptoms of type 2 diabetes related to high fat-fed rats more significantly than either treatment alone.

\section{CONCLUSION}

In conclusion, these results suggest that testosterone combined with voluntary exercise was beneficial in improving insulin resistance, glucose homeostasis and pancreas tissue apoptosis in diabetic and castrated diabetic rats. Reducing p53 protein level may be one of the mechanisms by which voluntary exercise combined with testosterone protect pancreas and Langerhans islets from apoptosis induced by hyperglycemia in type 2 diabetic castrated rats. Noteworthy, in the next our works following this study, molecular and histological studies conducted on isolated islets and identified beta cells.

Funding: This research was funded by Urmia University of Medical Sciences, Urmia, Iran, grant number 2252.

Acknowledgments: We are grateful to the employees in Departments of Medical Physiology in Urmia University of Medical Sciences, for their kind helps to this study.

Conflicts of Interest: The authors declare no conflict of interest. 


\section{REFERENCES}

1. Salas-Salvadó J, Martinez-Gonzalez M, Bullo M, Ros E: The role of diet in the prevention of type 2 diabetes. Nutr Metab Cardiovasc Dis. 2011;21:B32-B48.

2. Holman RR, Paul SK, Bethel MA, Matthews DR, Neil HAW:10-year follow-up of intensive glucose control in type 2 diabetes. N Engl J Med. 2008;359(15):1577-89.

3. Lim EL, Hollingsworth K, Aribisala BS, Chen M, Mathers J, Taylor R:Reversal of type 2 diabetes: normalisation of beta cell function in association with decreased pancreas and liver triacylglycerol. Diabetologia. 2011;54(10):250614.

4. Kahn S:The relative contributions of insulin resistance and beta-cell dysfunction to the pathophysiology of type 2 diabetes. Diabetologia. 2003;46(1):3-19.

5. Meier JJ, Bonadonna RC:Role of reduced $\beta$-cell mass versus impaired $\beta$-cell function in the pathogenesis of type 2 diabetes. Diabetes care. 2013;36(Supplement 2):S113-S9.

6. Butler AE, Janson J, Bonner-Weir S, Ritzel R, Rizza RA, Butler PC: $\beta$-cell deficit and increased $\beta$-cell apoptosis in humans with type 2 diabetes. Diabetes. 2003;52(1):102-10.

7. Lee H-K, Lee JK, Cho B:The role of androgen in the adipose tissue of males. The world journal of men's health. 2013;31(2):136-40.

8. Ding EL, Song Y, Malik VS, Liu S:Sex differences of endogenous sex hormones and risk of type 2 diabetes: a systematic review and meta-analysis. Jama. 2006;295(11):1288-99.

9. Haffner SM, Shaten J, Stem MP, Smith GD, Kuller L, Group MR:Low levels of sex hormone-binding globulin and testosterone predict the development of non-insulin-dependent diabetes mellitus in men. Am $\mathrm{J}$ Epidemiol 1996;143(9):889-97.

10. Morimoto S, Mendoza-Rodriguez C, Hiriart M, Larrieta M, Vital P, Cerbon M:Protective effect of testosterone on early apoptotic damage induced by streptozotocin in rat pancreas. Eur J Endocrinol. 2005;187(2):217-24.

11. Morimoto S, Fernandez-Mejia C, Romero-Navarro G, Morales-Peza N, Díaz-Sánchez V:Testosterone effect on insulin content, messenger ribonucleic acid levels, promoter activity, and secretion in the rat. Endocrinology. 2001;142(4):1442-7.

12. Kapoor D, Goodwin E, Channer K, Jones T:Testosterone replacement therapy improves insulin resistance, glycaemic control, visceral adiposity and hypercholesterolaemia in hypogonadal men with type 2 diabetes. Eur. J. Endocrinol.. 2006;154(6):899-906.

13. Schellenberg ES, Dryden DM, Vandermeer B, Ha C, Korownyk C:Lifestyle interventions for patients with and at risk for type 2 diabetes: a systematic review and meta-analysisAnn. Intern. Med. 2013;159(8):543-51.

14. Huang $\mathrm{H}-\mathrm{H}$, Farmer K, Windscheffel J, Yost K, Power M, Wright DE, Stehno-Bittel L:Exercise increases insulin content and basal secretion in pancreatic islets in type 1 diabetic mice. Exp. Diabetes Res.. 2011;2011.

15. Su S-H, Jen CJ, Chen $\mathrm{H}$-i:NO signaling in exercise training-induced anti-apoptotic effects in human neutrophils. Biochem. Biophys. Res. Commun. 2011;405(1):58-63.

16. Al-Jarrah $\mathrm{M}$, Obaidat $\mathrm{H}$, Bataineh $\mathrm{Z}$, Walton $\mathrm{L}$, Al-Khateeb A:Endurance exercise training protects against the upregulation of nitric oxide in the striatum of MPTP/probenecid mouse model of Parkinson's disease. NeuroRehabilitation. 2013;32(1):141-7.

17. Szalai Z, Szász A, Nagy I, Puskás LG, Kupai K, Király A, Berkó AM, Pósa A, et al.:Anti-inflammatory effect of recreational exercise in TNBS-induced colitis in rats: role of NOS/HO/MPO system. Oxid. Med. Cell. Longev. 2014;2014.

18. Paula FM, Leite NC, Borck PC, Freitas-Dias R, Cnop M, Chacon-Mikahil MP, Cavaglieri CR, Marchetti P, et al.:Exercise training protects human and rodent $\beta$ cells against endoplasmic reticulum stress and apoptosis. The FASEB journal. 2017;32(3):1524-36.

19. Wagner BA, Braddick VC, Batson CG, Cullen BH, Miller LE, Spritzer MD:Effects of testosterone dose on spatial memory among castrated adult male rats. Psychoneuroendocrinology. 2018;89:120-30.

20. Zhang M, Lv X-Y, Li J, Xu Z-G, Chen L:The characterization of high-fat diet and multiple low-dose streptozotocin induced type 2 diabetes rat model. Exp. Diabetes Res. 2009;2008.

21. Qian C, Zhu C, Yu W, Jiang X, Zhang F:High-fat diet/low-dose streptozotocin-induced type 2 diabetes in rats impacts osteogenesis and Wnt signaling in bone marrow stromal cells. PLoS One. 2015;10(8):e0136390.

22. Chen Y, Fu L, Han Y, Teng Y, Sun J, Xie R, Cao J: Testosterone replacement therapy promotes angiogenesis after acute myocardial infarction by enhancing expression of cytokines HIF-1a, SDF-1a and VEGF. Eur. J. Pharmacol. 2012;684(1-3):116-24.

23. Tsalouhidou S, Petridou A, Mougios V: Effect of chronic exercise on DNA fragmentation and on lipid profiles in rat skeletal muscle. Exp. Physiol. 2009;94(3):362-70. 
24. Katz A, Nambi SS, Mather K, Baron AD, Follmann DA, Sullivan G, Quon MJ:Quantitative insulin sensitivity check index: a simple, accurate method for assessing insulin sensitivity in humans. J. Clin. Endocrinol. Metab. 2000;85(7):2402-10.

25. Matthews D, Hosker J, Rudenski A, Naylor B, Treacher D, Turner R: Homeostasis model assessment: insulin resistance and $\beta$-cell function from fasting plasma glucose and insulin concentrations in man. Diabetologia. 1985;28(7):412-9.

26. Abdel-Raheem SM, Abdelwahab MA, EIAziz KMA:Evaluation of the protection efficacy of a sunscreen by measuring tissue p53 levels. J Egypt Women Dermatol Soc. 2010;7(1):22-7.

27. Roy S, Metya SK, Sannigrahi S, Rahaman N, Ahmed F:Treatment with ferulic acid to rats with streptozotocininduced diabetes: effects on oxidative stress, pro-inflammatory cytokines, and apoptosis in the pancreatic $\beta$ cell. Endocrine. 2013;44(2):369-79.

28. Muthusamy T, Dhevika S, Murugesan P, Balasubramanian K:Testosterone deficiency impairs glucose oxidation through defective insulin and its receptor gene expression in target tissues of adult male rats. Life Sci. 2007;81(7):534-42.

29. Miller K, Biller B, Schaub A, Pulaski-Liebert K, Bradwin G, Rifai N, Klibanski A:Effects of testosterone therapy on cardiovascular risk markers in androgen-deficient women with hypopituitarism. J. Clin. Endocrinol. Metab. 2007;92(7):2474-9.

30. Ar'Rajab A, AhréN B:Long-term diabetogenic effect of streptozotocin in rats. Pancreas. 1993;8(1):50-7.

31. Lee C-H, Kuo S-W, Hung Y-J, Hsieh C-H, He C-T, Yang T-C, Lian W-C, Chyi-Fan S, et al.:The effect of testosterone supplement on insulin sensitivity, glucose effectiveness, and acute insulin response after glucose load in male type 2 diabetics. Endocr. Res. 2005;31(2):139-48.

32. Holmang A, Svedberg J, Jennische E, Bjorntorp P:Effects of testosterone on muscle insulin sensitivity and morphology in female rats. Am. J. Physiol. Endocrinol. Metab. 1990;259(4):E555-E60.

33. Xia F, Xu X, Zhai H, Meng Y, Zhang H, Du S, Xu H, Wu H, et al.:Castration-induced testosterone deficiency increases fasting glucose associated with hepatic and extra-hepatic insulin resistance in adult male rats. Reprod. Biol. Endocrinol. 2013;11(1):106.

34. Grillo M, Jacobus A, Scalco R, Amaral F, Rodrigues D, Loss E, Wassermann G:Testosterone rapidly stimulates insulin release from isolated pancreatic islets through a non-genomic dependent mechanism. Horm. Metab. Res. 2005;37(11):662-5.

35. Saad F, Gooren L, Haider A, Yassin A:An exploratory study of the effects of 12 month administration of the novel long-acting testosterone undecanoate on measures of sexual function and the metabolic syndrome. Arch. Androl. 2007;53(6):353-7.

36. Groti K, Žuran I, Antonič B, Foršnarič L, Pfeifer M:The impact of testosterone replacement therapy on glycemic control, vascular function, and components of the metabolic syndrome in obese hypogonadal men with type 2 diabetes. The Aging Male. 2018;21(3):158-69.

37. Hanchang W, Semprasert N, Limjindaporn T, Yenchitsomanus P-t, Kooptiwut S:Testosterone protects against glucotoxicity-induced apoptosis of pancreatic $\beta$-cells (INS-1) and male mouse pancreatic islets. Endocrinology. 2013;154(11):4058-67.

38. Király MA, Bates HE, Kaniuk NA, Yue JT, Brumell JH, Matthews SG, Riddell MC, Vranic M:Swim training prevents hyperglycemia in ZDF rats: mechanisms involved in the partial maintenance of $\beta$-cell function. Am. J. Physiol. Endocrinol. Metab. 2008;294(2):E271-E83.

39. Delghingaro-Augusto V, Décary S, Peyot M-L, Latour MG, Lamontagne J, Paradis-Isler N, Lacharité-Lemieux M, Akakpo $\mathrm{H}$, et al.:Voluntary running exercise prevents $\beta$-cell failure in susceptible islets of the Zucker diabetic fatty rat. Am. J. Physiol. Endocrinol. Metab. 2011;302(2):E254-E64.

40. Miyazaki $Y$, Kawano H, Yoshida T, Miyamoto S, Hokamaki J, Nagayoshi $Y$, Yamabe H, Nakamura $H$, et al.:Pancreatic B-cell function is altered by oxidative stress induced by acute hyperglycaemia. Diabetic Medicine. 2007;24(2):154-60.

41. Pold R, Jensen LS, Jessen N, Buhl ES, Schmitz O, Flyvbjerg A, Fujii N, Goodyear LJ, et al.:Long-term AICAR administration and exercise prevents diabetes in ZDF rats. Diabetes. 2005;54(4):928-34.

42. Király MA, Bates HE, Yue JT, Goche-Montes D, Fediuc S, Park E, Matthews SG, Vranic M, et al.:Attenuation of type 2 diabetes mellitus in the male Zucker diabetic fatty rat: the effects of stress and non-volitional exercise. Metabolism. 2007;56(6):732-44.

43. Park Y-M, Padilla J, Kanaley JA, Zidon T, Welly RJ, Britton SL, Koch LG, Thyfault JP, et al.:Voluntary running attenuates metabolic dysfunction in ovariectomized low-fit rats. Med Sci Sports Exerc. 2017;49(2):254.

44. Asikainen T-M, Kukkonen-Harjula K, Miilunpalo S:Exercise for health for early postmenopausal women. Sports Med. 2004;34(11):753-78. 
45. Chen $\mathrm{C}-\mathrm{H}$, Huang $\mathrm{T}-\mathrm{H}$, Cheng $\mathrm{T}-\mathrm{L}$, Chang $\mathrm{C}-\mathrm{F}$, Wang $\mathrm{C}-\mathrm{Z}$, Wu M-H, Kang L:Exercise training ameliorates glucosamine-induced insulin resistance in ovariectomized rats. Menopause. 2017;24(6):617-23.

46. Flores-López LA, Díaz-Flores M, García-Macedo R, Ávalos-Rodríguez A, Vergara-Onofre M, Cruz M, ContrerasRamos A, Konigsberg M, et al.:High glucose induces mitochondrial p53 phosphorylation by p38 MAPK in pancreatic RINm5F cells. Mol. Biol. Rep. 2013;40(8):4947-58.

47. Raúl B-G, Antonio F-LL, Arturo B-GL, Miguel C, Rebeca G-M, Alejandro Á-R, Alejandra C-R, Margarita D-F, et al.:Hyperglycemia promotes p53-Mdm2 interaction but reduces p53 ubiquitination in RINm5F cells. Mol Cell Biochem. 2015;405(1-2):257-64.

48. Ortega-Camarillo C, Guzman-Grenfell A, Garcia-Macedo R, Rosales-Torres A, Avalos-Rodriguez A, Duran-Reyes G, Medina-Navarro R, Cruz M, et al.:Hyperglycemia induces apoptosis and p53 mobilization to mitochondria in RINm5F cells. Mol Cell Biochem. 2006;281(1-2):163-71.

49. Slentz CA, Tanner CJ, Bateman LA, Durheim MT, Huffman KM, Houmard JA, Kraus WE:Effects of exercise training intensity on pancreatic $\beta$-cell function. Diabetes care. 2009;32(10):1807-11.

50. Shih K-C, Kwok C-F:Exercise reduces body fat and improves insulin sensitivity and pancreatic $\beta$-cell function in overweight and obese male Taiwanese adolescentsBMC Pediatr. 2018;18(1):80.

51. Zhao J, Yang Z, He M, Wang Q, Hu R:Exercise preserves pancreatic $\beta$-cell mass and function in obese OLETF rats. 2018.

52. Laker RC, Gallo LA, Wlodek ME, Siebel AL, Wadley GD, McConell GK:Short-term exercise training early in life restores deficits in pancreatic $\beta$-cell mass associated with growth restriction in adult male rats. Am. J. Physiol. Endocrinol. Metab. 2011;301(5):E931-E40.

2021 by the authors. Submitted for possible open access publication under the terms and conditions of the Creative Commons Attribution (CC BY NC) license (https://creativecommons.org/licenses/by-nc/4.0/). 